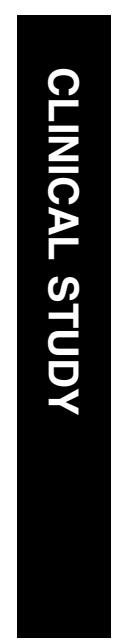

\title{
Changes of the ocular refraction among freshmen in National Taiwan University between 1988 and 2005
}

${ }^{1}$ Department of Ophthalmology, Taipei Medical University Hospital, Taipei, Taiwan

\section{${ }^{2}$ Department of} Ophthalmology, National Taiwan University Hospital, Taipei, Taiwan

${ }^{3}$ National Taiwan University College of Medicine, Taipei, Taiwan

Correspondence: LL-K Lin, Department of Ophthalmology, National Taiwan University Hospital, 7, Chung Shan South Road., Taipei, Taiwan 100, Taiwan Tel: + 88622356 2131; Fax: + 886223412875

E-mail: yfshih@

ha.mc.ntu.edu.tw

Received: 7 March 2008 Accepted in revised form: 20 May 2008

Published online: 13 June 2008

\begin{abstract}
Purpose The prevalence of myopia in Taiwan has been reported to be increasing in the sequential nationwide survey. The purpose of this study is to compare the change of ocular refraction among freshmen in 1988 and 2005 in National Taiwan University.

Methods The refractive status of freshmen in National Taiwan University in 2005 was examined. The refractive status and corneal radius of each student were measured with autorefractometer. The data was compared with the data obtained in 1988. All the refractions of the right eye were chosen and myopia was defined as a mean spherical equivalent of $-0.25 \mathrm{D}$ or more.

Results The mean refractive status of total 4686 freshmen was $-4.25 \pm 2.74 \mathrm{D}$ in 1988 $(-4.12 \pm 2.72 \mathrm{D}$ for males and $-4.41 \pm 2.75 \mathrm{D}$ for females). The prevalence of myopia was $91.3 \%$ (90.1\% for males and $\mathbf{9 2 . 8 \%}$ for females). The prevalence of high myopia (over $-6.0 \mathrm{D}$ ) was $23.5 \%$ (22.2\% for males and $25.1 \%$ for females). In 2005, the mean refractive status of total 3709 freshmen was $-4.93 \pm 2.82 \mathrm{D}(-4.93 \pm 2.83 \mathrm{D}$ for males and $-4.93 \pm 2.80 \mathrm{D}$ for females). The prevalence of myopia was $95.9 \%$ (95.9\% for males and $95.9 \%$ for females). The prevalence of high myopia was $38.4 \%$ (38.1\% for males and $38.8 \%$ for females).

Conclusions The prevalence and severity of myopia in freshmen of National Taiwan University increased significantly in 2005 compared to 1988. The distribution of refractive status in different college changed also. These findings may be explained by the early onset of myopia. Eye (2009) 23, 1168-1169; doi:10.1038/eye.2008.184; published online 13 June 2008
\end{abstract}

Keywords: myopia; ocular refraction; freshmen
T-J Wang ${ }^{1,2,3}$, T-H Chiang ${ }^{2}$, T-H Wang ${ }^{2,3}$, LL-K Lin' Li, $^{2,}$ and Y-F Shih ${ }^{2,3}$
Taiwan is one of the countries with high prevalence of myopia. ${ }^{1}$ The purpose of this study is to compare the change of ocular refraction among freshmen between 1988 and 2005 in National Taiwan University. ${ }^{2}$

The mean refractive status of total 4686 freshmen was $-4.25 \pm 2.74 \mathrm{D}$ in 1988 $(-4.12 \pm 2.72 \mathrm{D}$ for male and $-4.41 \pm 2.75 \mathrm{D}$ for female). In 2005, it was $-4.93 \pm 2.82 \mathrm{D}$ $(-4.93 \pm 2.83 \mathrm{D}$ for male and $-4.93 \pm 2.80 \mathrm{D}$ for female) of total 3709 freshmen. The result was shown in the Table 1 . The prevalence of myopia was $95.9 \%$ in 2005 , while it was $91.3 \%$ in 1988 . The prevalence of high myopia (over $-6.0 \mathrm{D}$ ) increased to $38.4 \%$ (38.1\% for male and $38.8 \%$ for female) in 2005, while it was $23.5 \%$ (22.2\% for male and $25.1 \%$ for female) in 1988 . The distribution curve in 2005 compared to 1988 was obviously more myopic-shifted. Detail analysis of refractive status among male and female freshmen in 1988 and 2005 was showed in Table 2. There was a significant difference between 1988 and 2005 ( $\chi^{2}$ test, $P<0.0001$ ). The incidence of both low myopia $(-0.25$ to $-3.0 \mathrm{D})$ and moderate myopia $(-3.0 \mathrm{D}$ to $-6.0 \mathrm{D})$ decreased around $5 \%$. However, the high myopic rate $(<-6.0 \mathrm{D})$ was increased more than $10 \%$. There was a significant increase in high myopia. (Fisher's exact test, $P<0.05)$. Besides, if we defined pathological myopia according to Tokoro's classification, ${ }^{3}$ the rate of pathological myopia $(<-8.0 \mathrm{D})$ in female and male in 2005 was 15.0 and $10.6 \%$, respectively.

The results of our studies demonstrated that the prevalence of myopia, especially high myopia increased among the freshmen in National Taiwan University. These findings may be explained by two possible reasons. First, we found the age of onset of myopia decreased from 12 years in 1983 to 8 years in 2000 in our previous nationwide survey. ${ }^{1}$ Second, myopia is influenced 
Table 1 The prevalence of myopia and high myopia

\begin{tabular}{llccc}
\hline & & Male & Female & Total \\
\hline 1988 & Prevalence of myopia & $90.1 \%(2373 / 2634)$ & $92.8 \%(1904 / 2052)$ & $91.3 \%(4277 / 4686)$ \\
& High myopia & $22.2 \%$ & $25.1 \%$ & $23.5 \%$ \\
& Refractive error & $-4.12 \pm 2.72 \mathrm{D}(n=2634)$ & $-4.41 \pm 2.75 \mathrm{D}(n=2052)$ & $-4.25 \pm 2.74 \mathrm{D}(n=4686)$ \\
& & & $95.9 \%(3558 / 3709)$ \\
2005 & Prevalence of myopia & $95.9 \%(1973 / 2057)$ & $95.9 \%(1585 / 1652)$ & $38.4 \%$ \\
& High myopia & $38.1 \%$ & $38.8 \%$ & $-4.93 \pm 2.82 \mathrm{D}(n=3709)$ \\
\hline
\end{tabular}

Table 2 The distribution of refractive status in 1988 and 2005

\begin{tabular}{lccrrrrr}
\hline & & Hyperopia & Emmetropia & \multicolumn{3}{c}{ Myopia } \\
\cline { 7 - 8 } 1988 & $>+2.0 D$ & $+2.0 \sim+0.26 D$ & $+0.25 \sim-0.25 D$ & $-0.25 \sim-3 D$ & $-3 \sim-6 D$ & $-6.0 \sim-10.0 D$ & $<-10.0 D$ \\
\hline Male (2634) & $9(0.3 \%)$ & $83(3.2 \%)$ & $108(4.1 \%)$ & $724(27.5 \%)$ & $1124(42.7 \%)$ & $546(20.7 \%)$ & $40(1.5 \%)$ \\
Female (2052) & $21(1.0 \%)$ & $46(2.2 \%)$ & $66(3.2 \%)$ & $491(23.9 \%)$ & $911(44.4 \%)$ & $472(23.0 \%)$ & $45(2.2 \%)$ \\
Total (4686) & $30(0.6 \%)$ & $129(2.8 \%)$ & $174(3.7 \%)$ & $1215(25.9 \%)$ & $2035(43.4 \%)$ & $1018(21.7 \%)$ & $85(1.8 \%)$ \\
& & & & & & & \\
2005 & $>+2.0 D$ & $+2.0 \sim+0.26 D$ & $+0.25 \sim-0.25 D$ & $-0.25 \sim-3 D$ & $-3 \sim-6 D$ & $-6.0 \sim-10.0 D$ & $<-10.0 D$ \\
\hline Male (2057) & $9(0.4 \%)$ & $20(0.9 \%)$ & $55(2.6 \%)$ & $418(20.3 \%)$ & $803(39.0 \%)$ & $667(32.4 \%)$ & $85(4.1 \%)$ \\
Female (1652) & $1(0.06 \%)$ & $25(1.5 \%)$ & $41(2.5 \%)$ & $319(19.3 \%)$ & $651(39.4 \%)$ & $541(32.7 \%)$ & $74(4.5 \%)$ \\
Total (3709) & $10(0.3 \%)$ & $45(1.2 \%)$ & $96(2.6 \%)$ & $737(19.9 \%)$ & $1454(39.2 \%)$ & $1208(32.6 \%)$ & $159(4.3 \%)$ \\
\hline
\end{tabular}

not only by genetic factors but also environmental factors. Environmental factors may play important role in the development or progression of myopia. ${ }^{4,5}$ This high-prevalence rate of high myopia and its complications strike us to make more close observation in this high educational group.

\section{References}

1 Lin LLK, Shih YF, Hsiao CK, Chen CJ. Prevalence of myopia in Taiwanese schoolchildren: 1983-2000. Ann Acad Med Singapore 2004; 33: 27-33.
2 Shih YF, Wang AH, Ko LS. Refractive status of medical students in National Taiwan University. Trans Soc Ophth Sinicae 1989; 28: 53-58.

3 Tokoro T. On the definition of pathologic myopia in group studies. Acta Ophthalmol Suppl 1988; 185: 107-108.

4 Fan DC, Lam DS, Lam RF, Lau JT, Chiong KS, Cheung EY et al. Prevalence, incidence, and progression of myopia of school children in Hong Kong. Invest Ophthalmol Vis Sci 2004; 45: 1071-1075.

5 Ling SL, Chen AJ, Rajan U, Cheah WM. Myopia in 10-yearold children: a case control study. Singapore Med J 1990; 31: 472-473. 